Review

\title{
Wear Performance of UHMWPE and Reinforced UHMWPE Composites in Arthroplasty Applications: A Review
}

\section{Juan C. Baena *, Jingping Wu and Zhongxiao Peng}

School of Mechanical and Manufacturing Engineering, The University of New South Wales, Sydney NSW 2052, Australia; E-Mails: j.p.wu@unsw.edu.au (J.W.); z.peng@unsw.edu.au (Z.P.)

* Author to whom correspondence should be addressed;

E-Mail: juan.baenavargas@student.unsw.edu.au; Tel.: +612-9358-4249.

Academic Editors: Amir Kamali and J. Philippe Kretzer

Received: 27 February 2015 / Accepted: 4 May 2015 / Published: 18 May 2015

\begin{abstract}
As the gold standard material for artificial joints, ultra-high-molecular-weight polyethylene (UHMWPE) generates wear debris when the material is used in arthroplasty applications. Due to the adverse reactions of UHMWPE wear debris with surrounding tissues, the life time of UHMWPE joints is often limited to 15-20 years. To improve the wear resistance and performance of the material, various attempts have been made in the past decades. This paper reviews existing improvements made to enhance its mechanical properties and wear resistance. They include using gamma irradiation to promote the cross-linked structure and to improve the wear resistance, blending vitamin E to protect the UHMWPE, filler incorporation to improve the mechanical and wear performance, and surface texturing to improve the lubrication condition and to reduce wear. Limitations of existing work and future studies are also identified.
\end{abstract}

Keywords: UHMWPE; wear resistance; mechanical properties; gamma irradiation; fillers; surface engineering

\section{Introduction}

Artificial joints are designed for a partial or complete replacement of articular joints affected by a degenerative disease known as osteoarthritis (OA). The estimated life span of a conventional artificial knee joint (AKJ) is around 15 to 20 years [1], mainly determined by the mechanical properties and wear 
resistance of the material used and the specific conditions of each patient [2]. Due to a continuous increase in orthopaedic surgical procedures and the fact that more young people are suffering OA [3], extending the lifespan of artificial joints is imperative and has become the most challenging issue in the improvement of artificial joint performance.

The degradation of artificial joints (AJ) is caused by many factors. Since AJ operate under sliding and rolling conditions [4], the surface degradation process is realised through specific wear mechanisms such as abrasion, adhesion and fatigue [5]. An increase in the external load and/or the surface roughness of the contact material(s) intensifies the wear process. The mechanical and physical properties of the materials also play an important role in the degradation process. The interaction of all these variables defines the tribological system of AJ and its degradation process.

The lifespan of AJ is closely linked to the wear resistance of its components. The wear of AJ affects the performance of the joint by causing hazardous biologic reactions in the body due to micron and sub-micron wear particles generated in the process [6]. Ultra-high-molecular-weight polyethylene (UHMWPE) has been considered as the gold standard material used in arthroplasty applications [7], especially for knee and hip artificial implant procedures. The UHMWPE, a component of polymer on metal (POM) joints, is a material subjected to severe material degradation and damage under sliding conditions due to its relatively high ductility, and relatively low hardness, Young's module and stiffness [8]. Large UHMWPE particles are not easily ingested by cells, proteins and/or body fluids [9], and, consequently, are less harmful than small sized wear debris. Small particles have a negative impact on the biological body system, affecting the integrity of cells, proteins and/or body fluids [9].

To enhance the performance of UHMWPE in terms of reducing its wear rate and wear particle generation, attempts have been made to improve the life span of the component. For example, the Hymaler, a high crystalline UHMWPE (with 73.2\%) was identified as a potential material for arthroplasty application, since this material presents a high resistance to fatigue and creep propagation. However, it is susceptible to oxidation related degradation, which affects its clinical performance. This material was replaced by Maraton crosslinked UHMWPE [10] in 1997. Regarding to UHMWPE composite, it also has been considered as a potential alternative to improve the wear performance of AJ. The UHMWPE reinforced with carbon fibers (CFR-UHMWPE), named Poly II, was used in orthopaedic implants in the 1970s. This composite was discontinued due to evidences on reduced crack resistance, rupture of the fibers on the surface and other issues [11].

Existing works are based on the following findings. It is well recognised that the mechanical properties of UHMWPE influence its load-bearing capacity [10]. Moreover, the wear resistance of an articular cartilage (AC) is related to the efficiency of its lubrication system [11]. Even though UHMWPE is considered to have a low friction during a sliding process, its low affinity between the synovial fluid and the polyethylene surface limits the effectiveness of lubrication of the component [12]. That low affinity is related to surface wettability which is described by the inclination of the fluid to cover the surface. A material with a good wettability tends to form a tribofilm on the surface that has the capability of carrying load and avoiding surface contact. An enhancement in the wettability of UHMWPE can improve the lubrication conditions, which would be reflected on the wear resistance performance [13]. The surface topographies of the material play an important role in the lubrication system and affect the wear rate [14]. Furthermore, studying the histology and surface appearance of degraded UHMWPE components are important to understand the most relevant wear mechanisms that affect the component integrity. 
To increase the life span of UHMWPE AJs, an improvement in the mechanical properties and/or surface and lubrication conditions can be achieved by various means including modifying the polymer structure, embedding filling materials to strengthen certain mechanical properties, and fabricating designed surface patterns on the outermost surface to improve lubrication conditions. This paper reviews reported studies on the improvement of the wear performance of UHMWPE composites for arthroplasty applications.

\section{Mechanical Properties and Manufacturing Process of UHMWPE}

UHMWPE is a polymer with outstanding mechanical and physical properties, including good wear and impact resistance, chemical inertness, lubricity and biocompatibility [15]. The mechanical and physical properties are intrinsic properties of the material, which can be modified in a manufacturing process. UHMWPE is widely used in industrial and clinical applications. Nowadays, around 2 million UHMWPE artificial joints are implanted every year [16]. The requirements of UHMWPE used for arthroplasty application are specified in ASTM standard F648 and ISO standard 5834-1. A raw material of this specific polyethylene is produced by Ticona-Celanese in two different powder classifications GUR1020 and GUR1050. They are classified according to their molecular weights, being around $3.5 \times$ $10^{6} \mathrm{~g} / \mathrm{mol}$ and 5.5-6.0 $\times 10^{6} \mathrm{~g} / \mathrm{mol}$ for GUR1020 and GUR1050, respectively [17].

Compression moulding and ram extrusion are the two widely performed manufacturing processes to form bulk UHMWPE pieces [18]. The compression moulding was the first manufacturing process used on UHMWPE powder in the 1950s and this manufacturing method is still being used by two companies, Orthoplastics and MediTECH, who produce compression mould sheets of GUR 1020 and 1050. In contrast, the ram extrusion of UHMWPE has been used for over 30 years and this process is used by a few companies to turn GUR 1020 and 1050 into ram extruded UHMWPE. Using this process, UHMWPE rods can be manufactured in a wide range of diameters, being the most commercial products used for orthopaedic purpose from 20 to $80 \mathrm{~mm}$ in diameter [19]. Due to its high molecular weight, the UHMWPE has a high viscosity even above the melt point, making this material complex to be processed by conventional screw extrusion [20]. After a UHMWPE block is formed, it is machined to an orthopaedic component.

Since the wear resistance is closely correlated to the mechanical properties, the UHMWPE mechanical properties have been modified using different methods, including the employed manufacturing processes. Kurtz [21] reported that the tensile yield and ultimate tensile properties did not present significant differences between the polyethylene types and manufacturing processes, while the elongation to failure was significantly different between the two processes and/or materials. The differences in the mechanical properties are presented in Figure 1.

\section{Improvements on the Wear Resistance of UHMWPE}

Studies on the modification of UHMWPE have been performed in order to improve its wear resistance and consequently its clinical performance. This section reviews a number of existing modification techniques including crystallinity, cross-linking, adding antioxidants and reinforced filling materials for enhancing mechanical properties, and surface engineering for improving its wear resistance. 


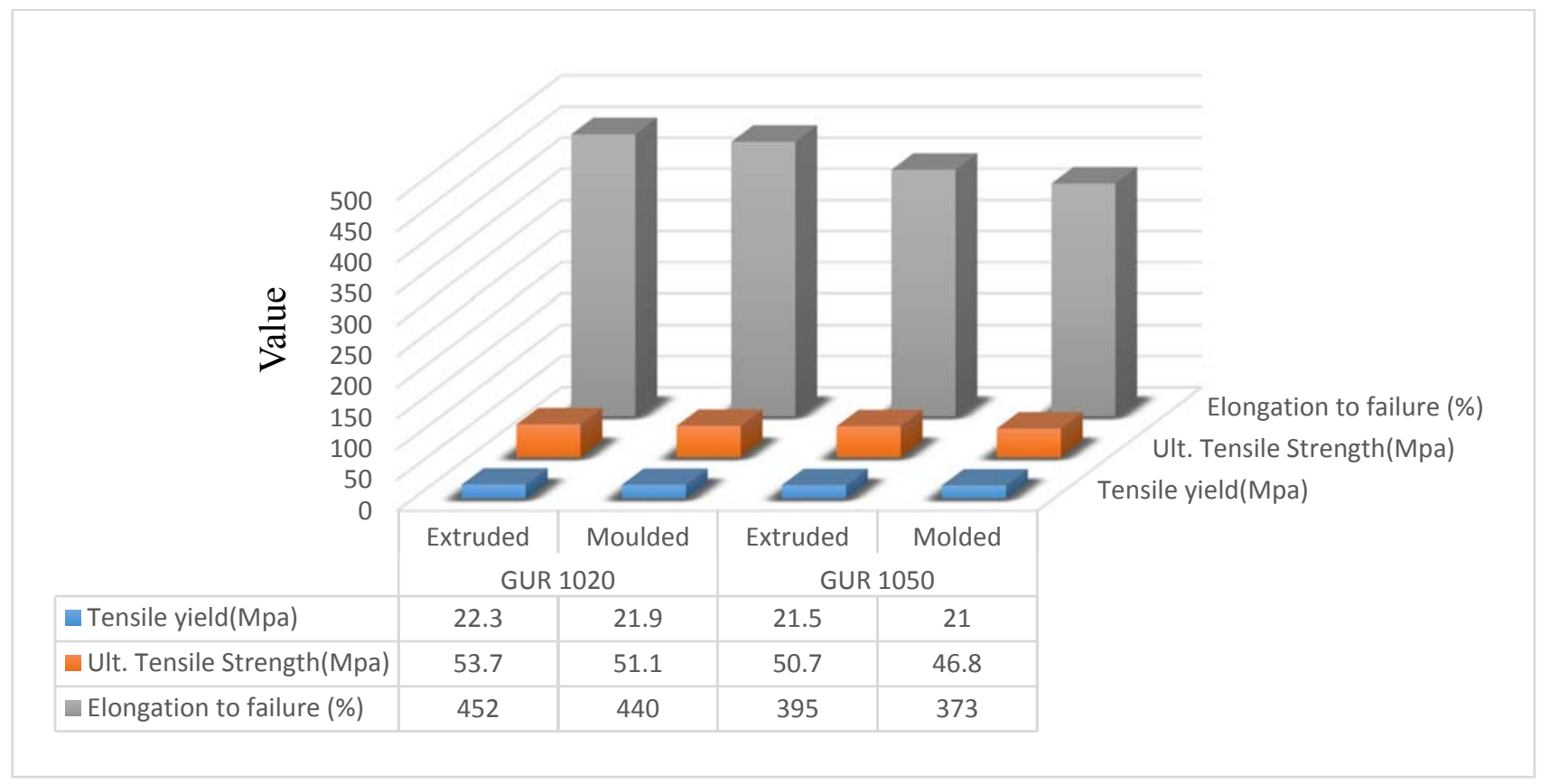

Figure 1. Mechanical properties of UHMWPE extruded and moulded. The data were taken from [21].

\subsection{Crystallinity of UHMWPE}

The mechanical and physical properties of UHMWPE are influenced by its crystallinity, which is related to the atomic or molecular arrangement, conforming a specific crystal structure [22]. The crystallinity of polymers is attributed to the specific arrangement of the molecular chains, forming crystalline regions or crystalline lamellae which are chain-folded molecules. Polymers are not totally crystalline and these lamellae are normally surrounded by random distributed molecules with amorphous regions [23].

Since the mechanical and physical properties of UHMWPE are highly affected by its microstructure and grade of crystallinity, it is expected that the wear performance can be improved by altering the microstructural conditions. Karuppiah et al. [1] evaluated the influence of crystallinity on the wear resistance of UHMWPE and reported that, with increasing the crystallinity, the friction force and the scratch depth tended to decrease. Their study suggested that the wear resistance increased with the degree of crystallinity. Similar results were reported by Wang and Ge [24] through varying mould pressures during the sample formation process. Furthermore, it was reported that the degree of crystallinity can be increased by controlling the material formation pressure and temperature. Heating the UHMWPE (with a molecular weight over 400,000) under high pressure followed by a posterior cooling process induces the formation of the crystalline structure. Lamellae with a thickness less than $12 \mathrm{~nm}$ were formed [25]. It was also reported that by holding the temperature above the melting point (around $110^{\circ} \mathrm{C}$ ) the chains of the polyethylene are able to fold and the crystalline lamellae is formed, resulting in an increase in the crystallinity of the material [1].

The degree of crystallinity in the material is estimated using differential scanning calorimetry (DSC) which determines the temperatures when the material experiences phase transitions such as crystallization and melting point. The phase transitions are evidenced by peaks at a specific temperature as shown in Figure 2 in [26]. The UHMWPE melting temperature is revealed by a sudden increase of the heat at 
around $137^{\circ} \mathrm{C}$. The degree of crystallinity $(\Delta \mathrm{Xc})$ of UHMWPE is calculated based on the melting heat of crystallinity, $\Delta \mathrm{Hm}$, which is the energy per unit mass required to melt the lamellae in the material [26]. The crystalline regions can be detected using transmission electron microscopy (TEM), which identifies the lamellae based on the white and gray contrast made with uranyl acetate. In TEM images the lamellae are revealed as white lines with defined dark borders and the amorphous region with grey contrast [16].

As stated before, the mechanical properties and the wear performances of UHMWPE are affected by its microstructure. Being a semicrystalline material, the degree of crystallinity of UHMWPE was estimated between $39 \%$ and $75 \%$ [17]. The lack of full crystallization imposes a limitation on its mechanical property enhancement. It is also known that the crystallinity of polymers is affected by temperature. It was found that, above 60 to $90{ }^{\circ} \mathrm{C}$, small crystallites could be dissolved [16], which might affect the mechanical performance at relatively low temperatures.

\subsection{Cross-Linked UHMWPE Using Gamma Irradiation}

Radiation crosslinking in UHMWPE was developed using high-dose radiation to reduce the ductility of the polymer, to increase the hardness and to improve the wear resistance of UHMWPE [27,28]. Gamma radiation and electron beam (e-beam) radiation are commonly used as an ionizing radiation source to generate free radicals on the polymer. The recombination of some free radicals form the crosslinks, which reduce the chain stretch of the material, and consequently, the plastic deformation is significantly reduced. The wear resistance is increased with the radiation dose, as can be seen in Figure 2. However, a high radiation dose accelerates the oxidation, which increases the failure of the material [29]. This is because excessive free radicals migrate to the interface (crystalline/amorphous) and react with diffused oxygen, causing oxidation and brittleness. The oxidation increases the wear rate, and consequently, the rate of particulate wear of the orthopaedic component [20]. Green et al. [30] stated that even though crosslinking can reduce the wear volume, particles released from an irradiated UHMWPE can be more biologically active and smaller than the particles from a non-irradiated one. These small particles increase the probability of osteolysis.

There are different alternatives to quench the free radicals and avoid oxidation. One approach is a thermal treatment after irradiation. It is stated that heating the material below the melt point can preserve the crystallinity and mechanical properties, but it does not completely eliminate the excess of free radicals [25]. In contrast, by heating the polymer to above the melting point, the crystalline regions are eliminated and the free radicals present good mobility. This combined effect improves the oxidative stability of the irradiated UHMWPE but reducing its crystallinity [31].

Electron beam (e-beam) and gamma irradiation produce similar reactions in the polymeric chains. In comparison to gamma irradiation, the penetration of the e-beam radiation is limited. However, since the e-beam irradiation process is considered adiabatic, it allows a major control of the temperature increase during the irradiation [31]. Both techniques are used for the irradiation treatment of commercially available UHMWPE for clinical use. Table 1 shows the irradiation processes of some trademarks and their corresponding mechanical properties.

Even when irradiated UHMWPE presents a significant improvement on the wear resistance, the susceptibility to oxidation due to free radicals is a concern. The thermal treatment after the irradiation process can increase the oxidation stability of UHMWPE but oxidation is not completely controlled. An 
additional and widely used alternative to reduce the free radicals after irradiation is blending Vitamin-E with the UHMWPE, which will be reviewed in the next section.

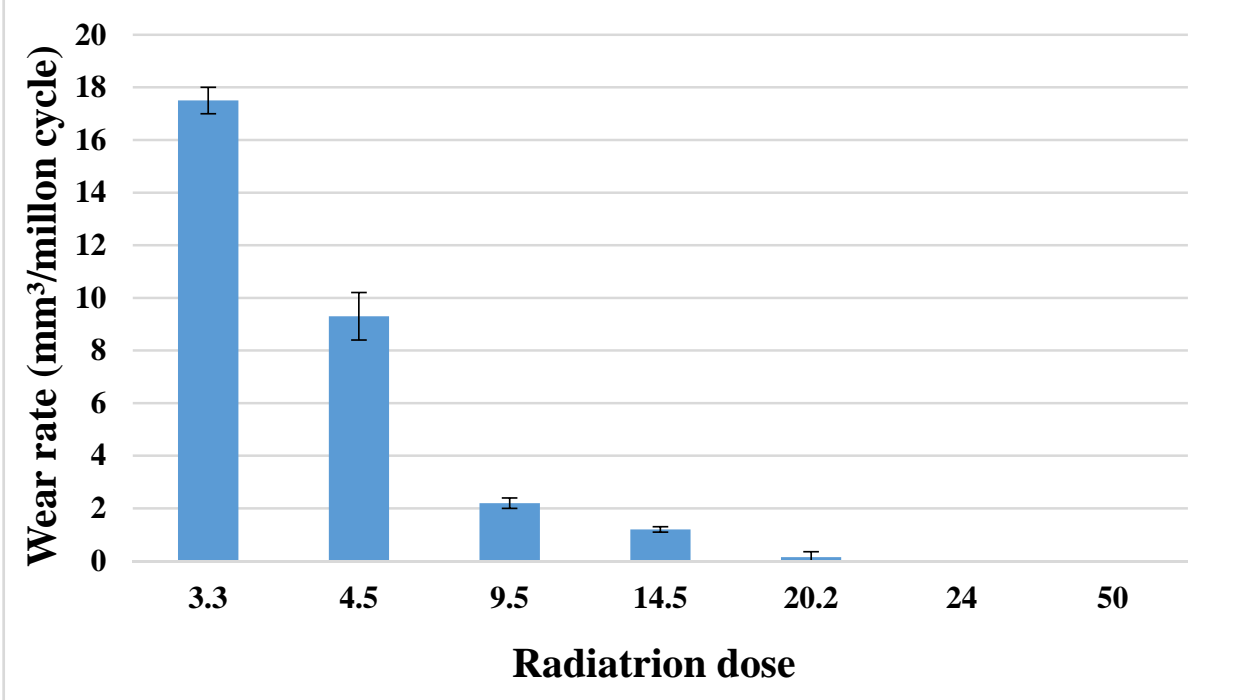

Figure 2. Variation of the wear rates of UHMWPE with different gamma radiation doses $(1 \mathrm{Mrad}=10 \mathrm{kGy})$. The data were taken from McKellop et al. [32].

\subsection{Vitamin-E-Stabilised UHMWPE}

As stated in the previous section, the crosslinking process induces the formation of free radicals in the crystalline phase, making the material susceptible to oxidation. These residual free radicals can migrate to the crystalline/amorphous interface and cause oxidation and reduction of UHMWPE elongation at break, tensile strength, fracture toughness and fatigue crack propagation resistance [33-38]. Therefore, to improve the oxidation resistance and the mechanical and fatigue strengths of cross-linked UHMWPE, antioxidant vitamin $\mathrm{E}$ is used to stabilise the radiation-induced free radicals [39-42]. The main role of vitamin $\mathrm{E}$ is to react with free radicals and protect the UHMWPE $[39,43]$. 
Table 1. Irradiation techniques employed on commercially available UHMWPE for clinical use and comparison between mechanical properties and the irradiation processes using GUR 1050 [31].

\begin{tabular}{|c|c|c|c|c|c|c|c|}
\hline Commercial Names & $\begin{array}{c}\text { Irradiation } \\
\text { Technique }\end{array}$ & $\begin{array}{c}\text { Irradiation } \\
\text { Temp }\end{array}$ & $\begin{array}{c}\text { Total Radiation } \\
\text { Dose (kGy) }\end{array}$ & $\begin{array}{c}\text { Post-Irradiation } \\
\text { Thermal Treatment }\end{array}$ & $\begin{array}{l}\text { Yield Strength } \\
\text { (Mpa) }( \pm \text { SD) }\end{array}$ & $\begin{array}{c}\text { Ultimate Tensile } \\
\text { Strength (Mpa) }( \pm \mathrm{SD})\end{array}$ & $\begin{array}{c}\text { True Elongation } \\
\text { to Break (\%) }\end{array}$ \\
\hline $\begin{array}{c}\text { UHMWPE } \\
\text { unirradiated }\end{array}$ & - & - & - & - & 21 & 50 & 340 \\
\hline $\begin{array}{l}\text { Longevity }^{a} \\
\text { (Zimmer) }^{b}\end{array}$ & E-beam & $40{ }^{\circ} \mathrm{C}$ & 100 & Melted & $21 \pm 1.0$ & $43 \pm 9.8$ & $240 \pm 35$ \\
\hline Durasul (Zimmer) & & $125^{\circ} \mathrm{C}$ & 95 & Melted & $20 \pm 0.7$ & $30 \pm 7.1$ & $280 \pm 74$ \\
\hline $\begin{array}{c}\text { Crossfire } \\
\text { (Stryker Howmedica) }\end{array}$ & & RT & 105 & $130^{\circ} \mathrm{C}$ & $24 \pm 1.3$ & $48 \pm 7.2$ & $280 \pm 37$ \\
\hline $\begin{array}{c}\text { Marathon } \\
\text { (DePuy/J and J) }\end{array}$ & Gamma & RT & 50 & Melted & $21 \pm 1.5$ & $56 \pm 5.7$ & $290 \pm 14$ \\
\hline $\begin{array}{c}\text { XLPE } \\
\text { (Smith \& Nephew) }\end{array}$ & & RT & 100 & Melted & $20 \pm 1.3$ & $56 \pm 7.1$ & $300 \pm 20$ \\
\hline
\end{tabular}

$\mathrm{RT}=$ Room Temperature $\mathrm{a}=$ trademark $\mathrm{b}=$ Manufacturer. 


\subsubsection{Methods of Vitamin E Blending}

Vitamin E can be incorporated into UHMWPE using two methods. The first method is diffusing vitamin $\mathrm{E}$ into UHMWPE after radiation crosslinking [44,45]. This method incorporates vitamin $\mathrm{E}$ into UHMWPE using a two-step process. The first step is post-radiation doping with vitamin $\mathrm{E}$, and the second step is a further homogenization into inert atmosphere $[44,45]$. The homogenization step is necessary since it can achieve an adequate antioxidant concentration throughout the implants. Using this method, the crosslinking efficiency of UHMWPE is not limited because vitamin $\mathrm{E}$ is not incorporated during irradiation. Furthermore, the amount of incorporated vitamin $\mathrm{E}$ is not affected by the crosslink density. Due to the saturation limit of the vitamin E blended UHMWPE at body temperature, the vitamin E concentration is approximately $0.7 \mathrm{wt} \%$ [46]. However, the UHMWPE has a risk of oxidation during irradiation and in storage until vitamin $\mathrm{E}$ is incorporated. The vitamin E-stabilised cross-linked UHMWPE, which is produced using this method, has been clinically used since 2007 [44,45,47-49].

The second method is blending a liquid antioxidant into the UHMWPE resin powder before the mixture consolidates into a near-implant form and radiation crosslinking is performed [39,50-52]. This method is easier and takes shorter time to obtain uniform vitamin E concentration throughout the implant compared with the first method [53]. However, the presence of vitamin E during the irradiation process reduces the efficiency of UHMWPE crosslinking, because vitamin E itself can act as a free radical scavenger [52]. Therefore, the concentration of vitamin $\mathrm{E}$ and the radiation dose must be optimized to achieve a good wear and oxidation resistance. The vitamin E concentration in the blend is limited to less than $0.3 \mathrm{wt} \%$ [54], and the radiation dose of the commercialized vitamin E-containing acetabular cup is normally less than $100 \mathrm{kGy}$.

More recently, some studies showed that the mechanical strength and fatigue resistance of vitamin E-stabilised UHMWPE can be further improved by some additional treatments. The further improvement of the wear resistance of vitamin E-stabilised irradiated UHMWPE was achieved by spatially manipulating the vitamin E concentration throughout the implant and limiting cross-linking to the surface [54-56]. Furthermore, the vitamin E-stabilised UHMWPE showed improved tensile and impact toughness and a good wear and oxidation resistance by high temperature melting after the introduction of vitamin $\mathrm{E}$ into UHMWPE [53].

\subsubsection{Effect of Vitamin E on Tribological and Mechanical Properties of UHMWPE}

Compared with conventional UHWMPE, vitamin E-stabilised UHMWPE has the ability to provide an improved tribological property [28]. Wear test results indicated that the wear rates of vitamin E-stabilised UHMWPE in clean serum and in serum with third-body particles had a 4-fold to 10-fold decrease from that of conventional UHMWPE [25]. The wear behaviour between vitamin E-stabilised UHMWPE and conventional UHMWPE using a knee joint simulator was compared, and the results indicated that vitamin E-stabilised UHMWPE had a consistently lower wear volume than that of the non-treated material [57]. It was believed vitamin E addition could prevent delamination caused by oxidation and fatigue, and therefore, significantly influence the life-span of the UHMWPE component.

The mechanical properties of vitamin E-stabilised UHMWPE are affected by vitamin E concentrations. The mechanical properties of vitamin E-stabilised UHMWPE are insensitive to the 
introduction of vitamin $\mathrm{E}$ up to the concentration of $0.4 \mathrm{wt} \%[51,52]$. When vitamin $\mathrm{E}$ concentration is in a range of $0.01-0.05 \mathrm{wt} \%$, vitamin $\mathrm{E}$ has a negligible effect on the mechanical properties of unsterilized and gamma sterilized UHMWPE [51]. Furthermore, for vitamin E concentration of $0 \mathrm{wt} \%, 0.1 \mathrm{wt} \%$, $0.2 \mathrm{wt} \%$ and $0.4 \mathrm{wt} \%$, the elastic modulus, elongation, tensile, and impact strength have no significant difference for both virgin and gamma sterilized UHMWPE [58]. However, for the $0.8 \mathrm{wt} \%$ vitamin $\mathrm{E}$ stabilised material, the elastic modulus and tensile strength were $20 \%$ lower than that of the virgin and gamma sterilized UHMWPE, while the elongation and impact strength remained at the baseline values [58]. To sum up, the previous studies [51,52,58] showed that vitamin $E$ alone with up to $0.4 \mathrm{wt} \%$ concentration have a marginal effect on the mechanical properties of UHMWPE. However, some studies $[44,57,59]$ suggested that vitamin E-stabilised UHMWPE has a significantly higher tensile strength, yield strength, elongation at break and fatigue resistance, especially at concentrations exceeding $0.1 \mathrm{wt} \%$ [59]. More detailed information on the mechanical properties of vitamin E-stabilised UHMWPE is shown in Table 2. Further studies on an optimal dose or an optimal dose range and better understanding of the mechanisms of the property improvement are needed.

\subsubsection{Limitations and Challenges}

Although vitamin $\mathrm{E}$ is an effective free radical scavenger, it impacts the crosslinking efficiency. Crosslinking radiation dose is an essential factor to the wear resistance. The introduction of vitamin E-stabilised material without any other changes in radiation exposure could result in a lower crosslinking density and has a potential trade off in wear resistance [40]. Therefore, it is a challenging work for orthopaedic implant researchers and manufacturers to optimise and determine an appropriate vitamin $\mathrm{E}$ concentration and radiation dose to achieve a good wear resistance.

\subsection{Fillers (CNFs, CNTs, Graphene and Hard Particles)}

A wide range of fillers are used to enhance the mechanical and lubrication properties of UHMWPE. Table 3 gives an overview of the commonly used filler materials and their effects on the mechanical properties and the wear performance. Details of the filler materials and their existing studies will be presented in the following sub-sections. 
Table 2. The mechanical properties of vitamin E-stabilised UHMWPEs.

\begin{tabular}{|c|c|c|c|c|c|c|c|c|c|}
\hline Resin & $\begin{array}{c}\text { VE } \\
\text { Concentration } \\
\text { (wt \%) } \\
\end{array}$ & $\begin{array}{c}\text { Tensile } \\
\text { Strength } \\
\text { Increase (\%) } \\
\end{array}$ & $\begin{array}{l}\text { Strain Break } \\
\text { Increase (\%) }\end{array}$ & $\begin{array}{c}\text { Yield } \\
\text { Strength } \\
\text { Increase (\%) }\end{array}$ & $\begin{array}{c}\text { Impact } \\
\text { Strength } \\
\text { Increase (\%) } \\
\end{array}$ & $\begin{array}{c}\text { Elastic } \\
\text { Modulus } \\
\text { Increase (\%) } \\
\end{array}$ & $\begin{array}{c}\text { Elongation } \\
\text { Increase (\%) }\end{array}$ & $\begin{array}{c}\text { Fatigue } \\
\text { Strength } \\
\text { Increase (\%) } \\
\end{array}$ & Ref \\
\hline $\begin{array}{c}\text { UHMWPE GUR } \\
1020 \text { and } 1050\end{array}$ & $0.01-0.05$ & $\begin{array}{c}\text { No significant } \\
\text { change }\end{array}$ & $\begin{array}{c}\text { No significant } \\
\text { change }\end{array}$ & - & - & - & - & - & [51] \\
\hline $\begin{array}{c}\text { UHMWPE GUR } \\
1020\end{array}$ & $0.1-0.4$ & $\begin{array}{c}\text { No significant } \\
\text { change }\end{array}$ & - & - & $\begin{array}{l}\text { No significant } \\
\text { change }\end{array}$ & $\begin{array}{c}\text { No significant } \\
\text { change }\end{array}$ & $\begin{array}{c}\text { No significant } \\
\text { change }\end{array}$ & - & [58] \\
\hline $\begin{array}{c}\text { UHMWPE GUR } \\
1020\end{array}$ & 0.8 & -20 & - & - & $\begin{array}{l}\text { No significant } \\
\text { change }\end{array}$ & -20 & $\begin{array}{l}\text { No significant } \\
\text { change }\end{array}$ & - & [58] \\
\hline $\begin{array}{c}\text { UHMWPE GUR } \\
1050\end{array}$ & - & - & - & - & - & - & - & 58 & [60] \\
\hline $\begin{array}{c}\text { UHMWPE GUR } \\
1050\end{array}$ & $0.1-0.3$ & 51 & - & 19 & - & - & -19 & - & {$[52]$} \\
\hline $\begin{array}{c}\text { UHMWPE GUR } \\
1050\end{array}$ & - & 36 & - & 4 & - & - & 32 & 35 & [25] \\
\hline UHMWPE & $0.1-0.3$ & - & - & - & - & - & - & $10-20$ & [59] \\
\hline
\end{tabular}




\subsubsection{Carbon Nanofibres (CNFs)}

Owing to the intrinsic properties and cytocompatibility of carbon nanofibres (CNF), incorporation of CNF to improve the mechanical and wear properties of UHMWPE receives increasing attention [61]. Studies on the mechanical properties of CNF reinforced polyethylene revealed that the material's yield stress, tensile modulus and hardness increased by the addition of a certain amount of CNFs. For example, it was reported that incorporation of $5 \mathrm{wt} \%$ CNFs resulted in an approximately $25 \%$ increase in the tensile modulus, while increasing the CNF content to $10 \mathrm{wt} \%$ led to a slightly additional benefit [62]. Similar trends were also observed for the hardness of CNF reinforced UHMWPE material [62]. The addition of the carbon nano-fibres results in an approximately linear increase in hardness. In addition, presence of the nano-fibre in the $10 \mathrm{wt} \%$ samples leads to an additional benefit in terms of a further increase in the hardness. The mechanical properties of CNF reinforced polyethylene are sensitive to the CNF concentration. In Sui's work [26], $0.5 \mathrm{wt} \%, 1.0 \mathrm{wt} \%$, and $3.0 \mathrm{wt} \% \mathrm{CNF}$ were added into UHMWPE. The tensile strength and tensile modulus of the UHMWPEs increased with the addition of CNFs, while a decrease appeared at $3 \mathrm{wt} \%$ content.

The presence of dispersed carbon nanofibres also can lead to a significantly improvement of wear performance of UHMWPE material. With the addition of $0.5-3 \mathrm{wt} \% \mathrm{CNFs}$, the wear rate of UHMWPEs decreased 56\%-58\% [26,60,63]. However, it was found that nanofiber agglomeration offset this enhancement. In Xu's study, the addition of $0.5 \mathrm{wt} \% \mathrm{CNF}$ resulted in an improved wear resistance, while a higher level $\mathrm{CNF}$ addition (3 $\mathrm{wt} \%$ ) resulted in a higher wear rate [64]. A similar trend was found in Galetz's study [62], in which with $5 \mathrm{wt} \% \mathrm{CNF}$, the nanocomposite showed a highly improved wear rate compared to the pure UHMWPE. Compared with $5 \mathrm{wt} \%$ CNF-reinforced UHMWPE, the wear rate increased at the presence of a larger CNF concentration $(10 \mathrm{wt} \%)$.

Table 3. Popularly used fillers and their effects on the mechanical properties and/or wear performance of UHMWPE.

\begin{tabular}{cccc}
\hline Fillers & Percentage of Inclusion & Improved Properties & Reduction in Wear Rate \\
\hline $\begin{array}{c}\text { Carbon nanofibers } \\
(\mathrm{CNF})[26,58,59,62,65]\end{array}$ & $0.5 \%-5 \%$ & Tensile strength & $56 \%-58 \%$ \\
\hline $\begin{array}{c}\text { Carbon nanotube } \\
\text { (CNTs) }[66-69]\end{array}$ & $0.1 \%-5 \%$ & $\begin{array}{c}\text { Tensile strength } \\
\text { Young's modulus } \\
\text { Toughness }\end{array}$ & $26 \%-86 \%$ \\
\hline Graphene [70-75] & $0.1 \%-1.0 \%$ & $\begin{array}{c}\text { Lubrication, tensile strength } \\
\text { Yield strength }\end{array}$ & $\begin{array}{c}2.5-4.5 \text { times } \\
(\text { depending on load })\end{array}$ \\
\hline Hard particles [76-79] & $10 \%-20 \%$ & Bearing loading capacity & $36 \%-60 \%$ \\
\hline
\end{tabular}

\subsubsection{Carbon Nanotube (CNTs)}

The introduction of carbon nanotubes (CNT) is a recent development that will likely make a new generation of advanced implant material possible. CNTs possess high strength, a high aspect ratio, and excellent thermal and electrical conductivity [80]. They can enhance the mechanical performance and wear resistance of UHMWPE, promote bone growth and act as an antioxidant. 
Experimental investigations on the mechanical properties of CNT reinforced polyethylene indicated that the tensile strength, Young's modulus and toughness of the material increased by the addition of a certain amount of CNTs [72,81]. In previous studies [81-84], with the addition of $0.1-5 \mathrm{wt} \% \mathrm{CNTs}$, the tensile strength and Young's modulus of reinforced UHMWPE increased 8\%-38\% and 5\%-100\%, respectively. An improvement in the UHMWPE toughness was also reported with the addiction of $1 \mathrm{wt} \%$ CNTs [68].

In addition to the improved mechanical properties, CNT-reinforced UHMWPE has gained intensive interest because of their good wear resistance. By the incorporation of $0.1-4 \mathrm{wt} \% \mathrm{CNTs}$, the wear rate of UHMWPEs decreased 26\%-86\% [80,81,83,69,85]. However, the wear performance of CNT-reinforced UHMWPE is sensitive to CNT concentrations and types. The friction coefficient of pure UHMWPE is approximately 0.05, while the friction coefficient increased slowly as CNTs were added from 0.1 to $0.5 \mathrm{wt} \%$ [80]. The weight loss of CNT-reinforced UHMWP was found to decrease with the increasing amount of CNT addition [80]. Furthermore, in Liu's study [86], $0.45 \mathrm{wt} \%$ multi-walled carbon nanotubes (MWCNTs), $0.1 \mathrm{wt} \%$ granular form carbon nanotubes and $0.5 \mathrm{wt} \%$ single-walled carbon nanotubes were blended into UHMWPE. The wear rates of these three types of CNT reinforced UHMWPEs were slightly higher than that of pure UHMWPE material.

Martinez-Morales et al. [87] reported that MWCNTs improve the oxidative resistance of the composite (MWCNT/UHMWPE) and some in vitro studies showed that bone cells could grow along CNTs [88]. It is an exciting prospect for acetabular sockets as the structured surface of CNTs composite could potentially encourage new bone growth on the outer surface of the prosthesis so that the bond between natural bone and prosthesis will be strengthened. Last but not least, CNTs can improve the antioxidant ability in the polymer matrix because of their radical accepting capacity [73].

\subsubsection{Graphene}

The outstanding mechanical and physical properties of graphene make this material a candidate to be used in UHMWPE composite as a component of AJs. This two-dimensional (2D) material has excellent mechanical properties, such as the Young modulus (0.5-1 Tpa), tensile strength ( 130 Gpa) and high thermal and electrical conductivity $\left(\sim 4.84 \times 10^{3} \mathrm{~W} / \mathrm{mk}\right.$ and $7600 \mathrm{~S} / \mathrm{m}$, respectively) [70,74]. These outstanding properties made this material suitable for different applications, including computing, nano and micro-electronical systems, and biomedical fields.

Graphene is produced using different methods. The graphene nanoplatelet (GNP) is obtained by the electrostatic spraying technique. The graphene oxide (GO) is obtained by treating the graphite with a strong oxidazer [71], resulting in a compound of carbon, oxygen and hydrogen. The reduced oxide graphene (RGO) is a result from chemical exfoliation of graphene [75]. The properties of graphene are affected by the employed method of acquisition.

Graphene has been added as a filling material in UHMWPE composite to improve the wear resistance of the UHMWPE component used for artificial implants. Previous studies have shown an improvement in the wear resistance of this component with an increase in the graphene content [72]. Lahiri et al. [77] evaluated the evolution of the wear resistance at the nano-scale by scratching the UHMWPE-GNP composite at different GNP concentrations (0.1, 0.5, and $1.0 \mathrm{wt} \%)$ and using three different loads $(100,200$ and $300 \mu \mathrm{N})$. The authors noticed that the wear resistance of the material improve by 4.5 times with a $1 \mathrm{wt} \%$ 
GNP, compared with the pure UHMWPE. The coefficient of friction (COF) did not report a significant increase for a higher GNP content, which may be associated to the released graphene on the scratch, lubricating the path and reducing the COF.

\subsubsection{Hard Particles}

In addition to CNFs and CNTs, particle reinforcements using other hard particles were reported to be a very promising method for an improvement in the wear performance of UHMWPE [78,79,89-91]. By means of incorporating Ti particles [89], Zirconium particles [78], Pt-Zr quasicrystal [79], natural coral particles [90], and quartz [91] into UHMWPE, the wear rates of the particle-reinforced UHMWPEs reduced from $36 \%$ to $60 \%$. The mechanism of this improvement is that these hard particles can effectively take bearing load to protect the polymer matrix and thus improve the wear resistance of UHMWPE. However, the worn off hard particles might also act as a third body in the tribological system to accelerate the wear rate [92].

\subsubsection{Limitations and Challenges}

The effective use of carbon nanofillers in UHMWPE depends upon its homogeneous dispersion throughout the polymer matrix. Due to the complexity of UHMWPE material, the incorporation of CNF or CNT into UHMWPE is greatly complicated by the extremely high viscosity of the polymer matrix. The agglomerations of carbon nanofillers with a size of several tens of microns could act as localized stress concentration points [62]. These weak points could be removed from the bulk material in a wear process, resulting in wear particles. The wear debris could act as a third body between the interfaces and accelerate the material degradation process.

The mechanical properties of hard particles, such as hardness, size and concentration, are essential factors to the wear performance of particle-reinforced UHMWPE. Further study is necessary to determine an optimal particle type, particle size and concentration to minimise or eliminate the side effects of the incorporated particles on the wear performance of UHMWPE material. It is also important to study the interaction of wear debris generated from the particle reinforced UHMWPE with surrounding tissues to evaluate and eliminate possible inflammatory reactions, which may cause osteolysis.

In summary, the key challenges of carbon nanofiller reinforced UHMNWPE for tribological application is the determination of type of carbon nanofiller, the optimisation of carbon nanofiller concentration, and the improvement of blending techniques. Furthermore, knowledge in the public domain about carbon nanofillers reinforced UHMWPE for orthopaedic prostheses remains in its infancy. Additional research is needed to comprehensively study the tribological properties and to warrant its biocompatibility.

\subsection{Surface Modification of UHMWPE}

When used to replace damaged or diseased joints, UHMWPE made joints interact with many different components such as hard bone, soft tissue, blood, and synovial fluid. Similar to other biomaterials, whose functionality is significantly influenced by the surface characteristics, the surface structures and textures of UHMWPE determine its biocompatibility, physicochemical surface properties (e.g., wettability, surface energy), mechanical properties (e.g., toughness and load-carrying capacity) and tribological 
performance. A large amount of studies were carried out on surface modification of UHMWPE to improve the function and lifetime of the artificial joints. This section reviews commonly used surface modification methods, in particular, surface texturing techniques for an improvement in the mechanical properties and wear resistance of UHMWPE materials.

\subsubsection{Surface Coating}

Coating techniques involve depositing a thin film on the base material or promoting the cross-linking reaction by changing the properties of the outmost surface which is reviewed in Section 3.2. They are used popularly to enhance the performance of biomaterials. A range of properties can be improved including osteoinductive properties [93], hydrophilicity [94], mechanical and biological properties [95,96], surface properties (e.g., surface free energy) [97], and biotribological properties [94]. Surface coating by adding materials on the top surface will be briefly reviewed in the next paragraph.

Commonly applied coating techniques include plasma-surface modification using plasma spraying, implantation or deposition techniques [98] to enhance the surface properties such as wear resistance, and hardness. In the process, often a thin layer of a hard metallic material is added on the bulk material to improve its properties. More recently, nylon coating [95] on UHMWPE was reported to achieve lower cytotoxicity, less wear debris-induced osteolysis, and superior mechanical properties compared to neat UHMWPE. Zirconium carbon nitrides $\left(\mathrm{ZrC}_{x} \mathrm{~N}_{1-x}\right)$ coatings with embedded silver nanoparticles [94] were used as a surface modification option for multifunctional purposes including antimicrobial effect, corrosion resistance and maintaining or even improving their mechanical and tribological performance. Hydrogenated diamond like carbon (DLCH) coating has been also tested on UHMWPE with a good performance on the wear resistance, hardness and biocompatibility [99]. Two groups of samples were tested at a sliding velocity of $0.05 \mathrm{~m} / \mathrm{s}$ and a load of $5.23 \mathrm{~N}$. The study reported a wear rate reduction of approximately $30 \%$ when the samples were surface coated with a thin layer $(<20 \mathrm{~nm})$ of DLCH. Nowadays, with the advancement of nanotechnology, nano-materials such as nano carbon tubes [96], have been used as a coating material to further improve the performance of the coating techniques.

\subsubsection{Ion Beam Surface Modification}

Ion implantation is used to generate UHMWPE surface layers that are integrated with the substrate and have a specified structure or composition. The ion-beam texturing process can be performed to produce either a square or a round pattern using an electron formed screen mesh mask to the surface. Compared with other coating methods, the advantages of ion beam surface modification are that this technique avoids the risk of delamination and that the process is extremely controllable and reproducible [100]. Improvement of the tribological behaviour, as well as the surface mechanical properties of polymeric materials, was reported in [101] and surface wear reduction was found on UHMWPE by using nitrogen ion implantation [102,103]. It is believed that this surface modification method has hardening and stiffening effects. It can also increase the wettability of the surface. Dong et al. reported a wear rate reduction from $1 \times 10^{-8} \mathrm{~mm}^{3} \mathrm{~N}^{-1} \mathrm{~m}^{-1}$ for the untreated samples to $0.1 \times 10^{-8} \mathrm{~mm}^{3} \mathrm{~N}^{-1} \mathrm{~m}^{-1}$ for the $\mathrm{PI}^{3}$ treated ones [12]. Traditional ion implantation technique involves line-of-sight processing and thus is not suitable for the treatment of bone implants with a complex shape and curved surface [104]. To overcome the limitation, plasma immersion ion implantation is used for improvement of the surface mechanical 
properties, biocompatibility, bioactivity, antibacterial activity and the wear performance of biomaterials. Nitrogen, oxygen and hydrogen implanted UHMWPE showed better wear resistance than those untreated $[105,106]$.

\subsubsection{Photolithography and Nanoimprint Lithography}

Photolithgraphy makes surface patterns with a mask. The process involves coating, etching and transferring a photo-resist layer to the surface of a bulk material whose surface properties need to be improved [103]. In the study conducted in [107], photolithograpy was used to generate dimples with a diameter of $50 \mu \mathrm{m}$, a depth of $15 \mu \mathrm{m}$ and the area density in a range of $5 \%$ to $40 \%$ on both stainless steel and UHMWPE surfaces. The study found that having dimples on the UHMWPE surface was more effective for friction reduction than on a stainless steel surface. At high load $(700 \mathrm{~N})$, only the patterned UHMWPE surface could effectively reduce friction.

With advances in 3D and nano technology, nanoimprint lithograph (NIL) has become a versatile technique to produce nano-patterns on the surface of UHMWPE. The technique has many attractive features including nano-scale resolution, high throughput, high controllability of 3D nanostructures, low cost, and ability of generating patterns over a large area [100]. NIL can generate features with a few nano-metre resolution on either flat or nonflat surfaces. It is used to improve the tribological properties of the surface of UHMWPE. In the study conducted in [108], the patterned UHMWPE surface had a reduction in the friction coefficient between $8 \%$ and $35 \%$ in comparison to the non-patterned surface when tested under a dry sliding condition and with normal load in a range of 60 to $200 \mathrm{mN}$.

\subsubsection{Laser Surface Texturing}

Texturing or surface engineering refers to the physical modification of the surface morphology, and is now accepted as an effective and feasible technique for friction reduction and improvement of wear resistance. Due to the interaction of two moving surfaces occurring at various scales from macro to nano scale [109], research on surface texturing at the micro- and nano-metre scale has recently been carried out with the majority of existing studies being in the micron scale.

Commonly used surface texturing techniques for UHMWPE are electrical discharge etching [110] and laser surface engineering [111]. Laser micro-machining is now widely used to modify the 3D surface textures of UHMWPE at both micro- and submicro-metre scales. This technique becomes a good alternative to a standard photolithographic process because it is rapid and clean [111]. Using experimental and/or simulation methods existing studies investigated the effects of dimple size, depth and area density on the friction and wear properties of UHMWPE and its counterpart.

One common outcome is that the micro-texture increases the loading-carrying capacity and the thickness of the joint lubricant film, resulting in a reduction in friction and wear [110,112-115]. Load effects were studied in [107,113] when dimple diameter was around 40-50 $\mu \mathrm{m}$. It was found that under a light load (17-100 N), surface textures on either UHMWPE or its steel counterpart reduced friction. At high load (e.g., $700 \mathrm{~N}$ in [107]), it was reported that only the textures on the UHMWPE surface could effectively reduce friction. Wang et al. [115] investigated the area ratio effects and found that an area ratio in a range of $20 \%-40 \%$ was ideal to maximise the total hydrodynamic pressure between the two moving surfaces. They also found that when dimples were fabricated on the surface of steel and at a light 
load, the area density of 5\%-15\% was effective for friction reduction. If the dimples were textured on the UHMWPE surface, the area density of $30 \%$ improved both friction and wear resistance under a water lubricated condition and at a relative high load. It is believed that by applying surface textures on either UHMWPE or steel surface, abrasive wear is reduced by improving the lubrication condition through storing wear particles and lubricant in dimples [110] and by reduction of frictional heating of the sliding surfaces [114].

\subsubsection{Limitations and Challenges}

Possibly due to the capability of current laser technology, only micro-sized dimples were fabricated on UHMWPE surfaces and their effects were investigated in existing studies. Other patterns, such as square, ellipse, need to be fabricated and examined to find an optimal surface texture for friction and wear reduction. Furthermore, nano-scale surface textures were reported to provide low friction and wear properties [108] and need to be studied further.

Modifying surface texture to improve the wear performance and life span of the material is a challenging and debatable topic. Although some encouraging outcomes have been achieved in the past as reviewed above, its long term effect needs further investigations. For example, Kelly et al. [116] evaluated the wear damage of the tibiofemoral articular surface and the mobile-bearing surface (refer to Figure 2A-D of [116]). It was reported that the UHMWPE components became degraded in a relative short time (three years) and the most predominant damages modes were scratching, burnishing and pitting. The scratches, in particular, were believed to be made by a third body wear caused by particles from surgery or particles of the bone cement. Due to the presence of wear debris generated in the wear process and other particles, the wear process and mechanism are often evolved with the surface texture. The initially designed surface morphologies can be modified in the wear process. The long term, practical effect of the surface modification approaches requires further studies.

\section{Conclusions}

The ability to replace diseased or traumatised natural joints with artificial prostheses in order to alleviate pain and disability has been one of the major successes in engineering and medicine over the last 50 years. Although UHMWPE has been used as the most popular artificial replacement material in clinical applications for five decades, continuous research has been conducted to improve the performance of the material so its service life can be further extended. This paper has reviewed reported methods for improving the mechanical properties through creating a cross-linked structure, using an irradiation process with and without vitamin E, and by adding micron or nano-particles. Surface engineering techniques for the improvement of the lubrication conditions are also reviewed. Existing studies have demonstrated that cross-linked UHMWPE by gamma radiation is an effective way to significantly improve the wear resistance of the material from a wear rate of about $20 \mathrm{~mm}^{3}$ per million cycles of untreated material to close to a zero wear rate for gamma radiated to $280 \mathrm{kGy}$. Including fillers can also improve the mechanical properties and wear resistance. However, the reported improvement varies from $25 \%$ to $86 \%$ depending on different filler materials, their concentrations and/or directions. Similarly, according to the reported results, surface modifications can improve the wear resistance from $30 \%$ for the surface coating of diamond like carbon to $90 \%$ using ion beam surface modification method. As wear 
is a material removal process, the long term effect of the surface texture modification methods need to be further studied. With advances in modern technology, it is anticipated that multi-approaches will be developed and used to improve the chain structure, to further strengthen the mechanical properties and to improve the lubrication condition simultaneously in future studies.

\section{Author Contributions}

Juan C. Baena drafted the mechanical properties and manufacturing process of UHMWPE section. He also collected and presented the materials in sections 3.1 and 3.2 of the paper. Jingping Wu drafted sections 3.3 and 3.4 while Zhongxiao Peng was responsible for section 3.5 and the overall flow and quality of this paper. The three authors worked together to draft the other parts of the paper including Abstract, Introduction and Conclusions.

\section{Conflicts of Interest}

The authors declare no conflict of interest.

\section{References}

1. Kanaga Karuppiah, K.S.; Bruck, A.L.; Sundararajan, S.; Wang, J.; Lin, Z.; Xu, Z.-H.; Li, X. Friction and wear behavior of ultra-high molecular weight polyethylene as a function of polymer crystallinity. Acta Biomater. 2008, 4, 1401-1410.

2. Garellick, G.; Maichou, H.; Herberts, P. Specific or general health outcome measures in the evaluation of total hip replacement. J. Bone Joint Surg. 1998, 80, 600-606.

3. Wayne, G. A National Public Health Agenda for Osteoarthritis; Centers for Disease Control and Prevention: DeKalb County, GA, USA, 2010.

4. Delport, H.P.; Banks, S.A.; De Schepper, J.; Bellemans, J. A kinematic comparison of fixed- and mobile-bearing knee replacements. J. Bone Joint Surg. Br. 2006, 88, 1016-1021.

5. Williams, J.A. Wear and wear particles—Some fundamentals. Tribol. Int. 2005, 38, 863-870.

6. Jin, Z.; Fisher, J. 2-Tribology in joint replacement. In Joint Replacement Technology; Revell, P.A., Ed.; Woodhead Publishing: Sawston, UK, 2008; pp. 31-55.

7. Bono, J.V.; Scott, R.D. Revision Total Knee Arthroplasty; Springer: Berlin/Heidelberg, Germany, 2005 ; p. 292.

8. Bhushan, B. Adhesion and stiction: Mechanisms, measurement techniques, and methods for reduction. J. Vac. Sci. Technol. B 2003, 21, doi:10.1116/1.1627336.

9. Jacobs, J.J.; Skipor, A.K.; Patterson, L.M.; Hallab, N.J.; Paprosky, W.G.; Black, J.; Galante, J.O. Metal release in patients who have had a primary total hip arthroplasty. A prospective, controlled, longitudinal study. J. Bone Joint Surg. Am. 1998, 80, 1447-1458.

10. Shi, W.; Li, X.Y.; Dong, H. Preliminary investigation into the load bearing capacity of ion beam surface modified UHMWPE. J. Mater. Sci. 2004, 39, 3183-3186.

11. Pearle, A.D.; Warren, R.F.; Rodeo, S.A. Basic science of articular cartilage and osteoarthritis. Clin. Sports Med. 2005, 24, 1-12. 
12. Dong, H.; Shi, W.; Bell, T. Potential of improving tribological performance of UHMWPE by engineering the Ti6Al4V counterfaces. Wear 1999, 225-229, 146-153.

13. Deng, Y.; Xiong, D.; Wang, K. Biotribological properties of UHMWPE grafted with AA under lubrication as artificial joint. J. Mater. Sci. Mater. Med. 2013, 24, 2085-2091.

14. Liao, Y.; Hoffman, E.; Wimmer, M.; Fischer, A.; Jacobs, J.; Marks, L. CoCrMo metal-on-metal hip replacements. Phys. Chem. Chem. Phys. 2013, 15, doi:10.1039/c1032cp42968c.

15. Zhang, H.-X.; Shin, Y.-J.; Lee, D.-H.; Yoon, K.-B. Preparation of ultra high molecular weight polyethylene with $\mathrm{MgCl}_{2} / \mathrm{TiCl}_{4}$ catalyst: Effect of internal and external donor on molecular weight and molecular weight distribution. Polymer Bull. 2011, 66, 627-635.

16. Kurtz, S.M. Chapter 1-A primer on uhmwpe. In UHMWPE Biomaterials Handbook, 2nd ed; Kurtz, S.M., Ed.; Academic Press: Boston, MA, USA, 2009; pp. 1-6.

17. Edidin, A.A.; Kurtz, S.M. Influence of mechanical behavior on the wear of 4 clinically relevant polymeric biomaterials in a HIP simulator. J. Arthroplast. 2000, 15, 321-331.

18. Brach del Prever, E.M.; Bistolfi, A.; Bracco, P.; Costa, L. UHMWPE for arthroplasty: Past or future? J. Orthop. Traumatol. 2009, 10, 1-8.

19. Kurtz, S.M. Chapter 2-From ethylene gas to uhmwpe component: The process of producing orthopedic implants. In The UHMWPE Handbook; Kurtz, S.M., Ed.; Academic Press: San Diego, CA, USA, 2004; pp. 13-36.

20. Lim, K.L.K.; Ishak, Z.A.M.; Ishiaku, U.S.; Fuad, A.M.Y.; Yusof, A.H.; Czigany, T.; Pukanszky, B.; Ogunniyi, D.S. High-density polyethylene/ultrahigh-molecular-weight polyethylene blend. I. The processing, thermal, and mechanical properties. J. Appl. Polymer Sci. 2005, 97, 413-425.

21. Kurtz, S.M. Chapter 2-From ethylene gas to UHMWPE component: The process of producing orthopedic implants. In UHMWPE Biomaterials Handbook, 2nd ed.; Kurtz, S.M., Ed.; Academic Press: Boston, MA, USA, 2009; pp. 7-19.

22. Ayache, J.; Beaunier, L.; Boumendil, J.; Ehret, G.; Laub, D. Introduction to Materials; Springer: Berlin/Heidelberg, Germany, 2010; pp. 3-31.

23. McKeen, L.W. 3-Plastics used in medical devices. In Handbook of Polymer Applications in Medicine and Medical Devices; Ebnesajjad, K.M., Ed.; William Andrew Publishing: Oxford, UK, 2014; pp. 21-53.

24. Wang, S.; Ge, S. The mechanical property and tribological behavior of UHMWPE: Effect of molding pressure. Wear 2007, 263, 949-956.

25. Oral, E.; Christensen, S.D.; Malhi, A.S.; Wannomae, K.K.; Muratoglu, O.K. Wear resistance and mechanical properties of highly cross-linked, ultrahigh-molecular weight polyethylene doped with vitamin E. J. Arthroplasty 2006, 21, 580-591.

26. Sui, G.; Zhong, W.H.; Ren, X.; Wang, X.Q.; Yang, X.P. Structure, mechanical properties and friction behavior of UHMWPE/HDPE/carbon nanofibers. Mater. Chem. Phys. 2009, 115, 404-412.

27. Medel, F.J.; Puertolas, J.A. Wear resistance of highly cross-linked and remelted polyethylenes after ion implantation and accelerated ageing. Proc. Inst. Mech. Eng. Part H J. Eng. Med. 2008, 222, 877-885.

28. Oral, E.; Godleski Beckos, C.A.; Lozynsky, A.J.; Malhi, A.S.; Muratoglu, O.K. Improved resistance to wear and fatigue fracture in high pressure crystallized vitamin E-containing ultra-high molecular weight polyethylene. Biomaterials 2009, 30, 1870-1880. 
29. Jahan, M.S. Chapter 29-Esr insights into macroradicals in uhmwpe. In Uhmwpe Biomaterials Handbook, 2nd ed.; Kurtz, S.M., Ed.; Academic Press: Boston, MA, USA, 2009; pp. 433-450.

30. Green, T.R.; Fisher, J.; Stone, M.H.; Wroblewski, B.M.; Ingham, E. Polyethylene particles of a 'critical size' are necessary for the induction of cytokines by macrophages in vitro. Biomaterials 1998, 19, 2297-2302.

31. Muratoglu, O.K. Chapter 13-Highly crosslinked and melted UHMWPE. In UHMWPE Biomaterials Handbook, 2nd ed.; Kurtz, S.M., Ed.; Academic Press: Boston, MA, USA, 2009; pp. 197-204.

32. McKellop, H.; Shen, F.W.; Lu, B.; Campbell, P.; Salovey, R. Development of an extremely wear-resistant ultra high molecular weight polyethylene for total hip replacements. J. Orthop. Res. 1999, 17, 157-167.

33. Furmanski, J.; Anderson, M.; Bal, S.; Greenwald, A.S.; Halley, D.; Penenberg, B.; Ries, M.; Pruitt, L. Clinical fracture of cross-linked UHMWPE acetabular liners. Biomaterials 2009, 30, 5572-5582.

34. Costa, L.; Luda, M.P.; Trossarelli, L. Ultra-high molecular weight polyethylene: I. Mechano-oxidative degradation. Polymer Degrad. Stab. 1997, 55, 329-338.

35. Costa, L.; Luda, M.P.; Trossarelli, L.; Brach del Prever, E.M.; Crova, M.; Gallinaro, P. In vivo uhmwpe biodegradation of retrieved prosthesis. Biomaterials 1998, 19, 1371-1385.

36. Premnath, V.; Harris, W.H.; Jasty, M.; Merrill, E.W. Gamma sterilization of UHMWPE articular implants: An analysis of the oxidation problem. Biomaterials 1996, 17, 1741-1753.

37. Stea, S.; Antonietti, B.; Baruffaldi, F.; Visentin, M.; Bordini, B.; Sudanese, A.; Toni, A. Behavior of hylamer polyethylene in hip arthroplasty: Comparison of two gamma sterilization techniques. Int. Orthop. 2006, 30, 35-38.

38. Oral, E.; Malhi, A.S.; Muratoglu, O.K. Mechanisms of decrease in fatigue crack propagation resistance in irradiated and melted UHMWPE. Biomaterials 2006, 27, 917-925.

39. Bracco, P.; Oral, E. Vitamin E-stabilized UHMWPE for total joint implants: A review. Clin. Orthop. Relat. Res. 2011, 469, 2286-2293.

40. Kurtz, S.M. Chapter 16 vitamin-E-blended UHMWPE biomaterials. In UHMWPE Biomaterials Handbook, 2nd ed.; Academic Press: Boston, MA, USA, 2009; pp. 1-6.

41. Bracco, P.; Brunella, V.; Zanetti, M.; Luda, M.P.; Costa, L. Stabilisation of ultra-high molecular weight polyethylene with vitamin E. Polymer Degrad. Stab. 2007, 92, 2155-2162.

42. Shibata, N.; Tomita, N.; Onmori, N.; Kato, K.; Ikeuchi, K. Defect initiation at subsurface grain boundary as a precursor of delamination in ultrahigh molecular weight polyethylene. J. Biomed. Mater. Res. Part A 2003, 67A, 276-284.

43. Kiyose, C.; Ueda, T. Vitamin E distribution and metabolism of tocopherols and tocotrienols in vivo. J. Clin. Biochem. Nutr. 2004, 35, 47-52.

44. Oral, E.; Wannomae, K.K.; Hawkins, N.; Harris, W.H.; Muratoglu, O.K. A-tocopherol-doped irradiated UHMWPE for high fatigue resistance and low wear. Biomaterials 2004, 25, 5515-5522.

45. Oral, E.; Wannomae, K.K.; Rowell, S.L.; Muratoglu, O.K. Diffusion of vitamin E in ultra-high molecular weight polyethylene. Biomaterials 2007, 28, 5225-5237.

46. Oral, E.; Muratoglu, O. Vitamin E diffused, highly crosslinked UHMWPE: A review. Int. Orthop. (SICOT) 2011, 35, 215-223. 
47. Oral, E.; Rowell, S.L.; Muratoglu, O.K. The effect of $\alpha$-tocopherol on the oxidation and free radical decay in irradiated uhmwpe. Biomaterials 2006, 27, 5580-5587.

48. Wannomae, K.K.; Christensen, S.D.; Micheli, B.R.; Rowell, S.L.; Schroeder, D.W.; Muratoglu, O.K. Delamination and adhesive wear behavior of $\alpha$-tocopherol-stabilized irradiated ultrahigh-molecular-weight polyethylene. J. Arthroplasty 2010, 25, 635-643.

49. Haider, H.; Weisenburger, J.N.; Kurtz, S.M.; Rimnac, C.M.; Freedman, J.; Schroeder, D.W.; Garvin, K.L. Does vitamin E-stabilized ultrahigh-molecular-weight polyethylene address concerns of cross-linked polyethylene in total knee arthroplasty? J. Arthroplasty 2012, 27, 461-469.

50. Lerf, R.; Zurbrügg, D.; Delfosse, D. Use of vitamin e to protect cross-linked uhmwpe from oxidation. Biomaterials 2010, 31, 3643-3648.

51. Kurtz, S.M.; Dumbleton, J.; Siskey, R.S.; Wang, A.; Manley, M. Trace concentrations of vitamin E protect radiation crosslinked UHMWPE from oxidative degradation. J. Biomed. Mater. Res. Part A 2009, 90A, 549-563.

52. Oral, E.; Greenbaum, E.S.; Malhi, A.S.; Harris, W.H.; Muratoglu, O.K. Characterization of irradiated blends of alpha-tocopherol and UHMWPE. Biomaterials 2005, 26, 6657-6663.

53. Fu, J.; Doshi, B.N.; Oral, E.; Muratoglu, O.K. High temperature melted, radiation cross-linked, vitamin E stabilized oxidation resistant UHMWPE with low wear and high impact strength. Polymer 2013, 54, 199-209.

54. Oral, E.; Godleski Beckos, C.; Malhi, A.S.; Muratoglu, O.K. The effects of high dose irradiation on the cross-linking of vitamin E-blended ultrahigh molecular weight polyethylene. Biomaterials 2008, 29, 3557-3560.

55. Muratoglu, O.K.; O’Connor, D.O.; Bragdon, C.R.; Delaney, J.; Jasty, M.; Harris, W.H.; Merrill, E.; Venugopalan, P. Gradient crosslinking of uhmwpe using irradiation in molten state for total joint arthroplasty. Biomaterials 2002, 23, 717-724.

56. Oral, E.; Neils, A.; Muratoglu, O.K. High vitamin E content, impact resistant UHMWPE blend without loss of wear resistance. J. Biomed. Mater. Res. Part B 2015, 103, 790-797.

57. Teramura, S.; Sakoda, H.; Terao, T.; Endo, M.M.; Fujiwara, K.; Tomita, N. Reduction of wear volume from ultrahigh molecular weight polyethylene knee components by the addition of vitamin $\mathrm{E}$. J. Orthop. Res. 2008, 26, 460-464.

58. Wolf, C.; Krivec, T.; Lederer, K.; Schneider, W. Examination of the suitability of alpha-tocopherol as a stabilizer for ultra-high molecular weight polyethylene used for articulating surfaces in joint endoprostheses. J. Mater. Sci. Mater. Med. 2002, 13, 185-189.

59. Tomita, N.; Kitakura, T.; Onmori, N.; Ikada, Y.; Aoyama, E. Prevention of fatigue cracks in ultrahigh molecular weight polyethylene joint components by the addition of vitamin E. J. Biomed. Mater. Res. 1999, 48, 474-478.

60. Wood, W.J.; M, R.G.; Zhong, W.H. Improved wear and mechanical properties of UHMWPE-carbon nanofiber composites through an optimized paraffin-assisted melt-mixing process. Compos. Part B 2011, 42, 584-891.

61. Rachel, L.; Price, K.A.T.J.W. Improved osteoblast viability in the presence of smaller nanometre dimensioned carbon fibres. Nanotechnology 2004, 15, 892-900. 
62. Galetz, M.C.; Blaß, T.; Ruckdäschel, H.; Sandler, J.K.W.; Altstädt, V.; Glatzel, U. Carbon nanofibre-reinforced ultrahigh molecular weight polyethylene for tribological applications. J. Appl. Polymer Sci. 2007, 104, 4173-4181.

63. Wood, B.L.; Zhong, W. Influence of phase morphology on the sliding wear of polyethylene blends filled with carbon nanofibers. Polymer Eng. Sci. 2010, 50, 613-623.

64. Xu, S.; Aydar, A.; Liu, T.; Weston, W.; Tangpong, X.W.; Akhatov, I.S.; Zhong, W.-H. Wear of carbon nanofiber reinforced HDPE nanocomposites under dry sliding condition. J. Nanotechnol. Eng. Med. 2012, 3, 041003.

65. Price, R.L.; Haberstroh, K.M.; Webster, T.J. Improved osteoblast viability in the presence of smaller nanometre dimensioned carbon fibres. Nanotechnology 2004, 15, 892-900.

66. Bakshi, S.R.; Tercero, J.E.; Agarwal, A. Synthesis and characterization of multiwalled carbon nanotube reinforced ultra high molecular weight polyethylene composite by electrostatic spraying technique. Compos. Part A 2007, 38, 2493-2499.

67. Campo, N.; Visco, A.M. Incorporation of carbon nanotubes into ultra high molecular weight polyethylene by high energy ball milling. Int. J. Polymer Anal. Charact. 2010, 15, 438-449.

68. Ruan, S.L.; Gao, P.; Yang, X.G.; Yu, T.X. Toughening high performance ultrahigh molecular weight polyethylene using multiwalled carbon nanotubes. Polymer 2003, 44, 5643-5654.

69. Xue, Y.; Wu, W.; Jacobs, O.; Schadel, B. Tribological behaviour of UHMWPE/HDPE blends reinforced with multi-wall carbon nanotubes. Polymer Test. 2006, 25, 221-229.

70. Kuilla, T.; Bhadra, S.; Yao, D.; Kim, N.H.; Bose, S.; Lee, J.H. Recent advances in graphene based polymer composites. Prog. Polymer Sci. 2010, 35, 1350-1375.

71. Min, C.; Nie, P.; Song, H.-J.; Zhang, Z.; Zhao, K. Study of tribological properties of polyimide/graphene oxide nanocomposite films under seawater-lubricated condition. Tribol. Int. 2014, 80, 131-140.

72. Puértolas, J.A.; Kurtz, S.M. Evaluation of carbon nanotubes and graphene as reinforcements for UHMWPE-based composites in arthroplastic applications: A review. J. Mech. Behav. Biomed. Mater. 2014, 39, 129-145.

73. Shi, X.; Wang, J.; Jiang, B.; Yang, Y. Hindered phenol grafted carbon nanotubes for enhanced thermal oxidative stability of polyethylene. Polymer 2013, 54, 1167-1176.

74. Soldano, C.; Mahmood, A.; Dujardin, E. Production, properties and potential of graphene. Carbon 2010, 48, 2127-2150.

75. Stankovich, S.; Dikin, D.A.; Piner, R.D.; Kohlhaas, K.A.; Kleinhammes, A.; Jia, Y.; Wu, Y.; Nguyen, S.T.; Ruoff, R.S. Synthesis of graphene-based nanosheets via chemical reduction of exfoliated graphite oxide. Carbon 2007, 45, 1558-1565.

76. Ge, S.; Zhang, D.; Wang, Q. Biotribological behaviour of ultra-high molecular weight polyethylene composites containing Ti in a hip joint simulator. Proc. Inst. Mech. Eng. Part J. 2007, 221, 307-313.

77. Lahiri, D.; Hec, F.; Thiesse, M.; Durygin, A.; Zhang, C.; Agarwal, A. Nanotribological behavior of graphene nanoplatelet reinforced ultra high molecular weight polyethylene composites. Tribol. Int. 2014, 70, 165-169.

78. Plumlee, K.; Schwartz, C.J. Improved wear resistance of orthopaedic UHMWPE by reinforcement with zirconium particles. Wear 2009, 267, 710-717. 
79. Schwartz, C.J.; Bahadur, S.; Mallapragada, S.K. Effect of crosslinking and Pt-Zr quasicrystal fillers on the mechanical properties and wear resistance of uhmwpe for use in artificial joints. Wear 2007, 263, 1072-1080.

80. Zoo, Y.-S.; An, J.-W.; Lim, D.-P.; Lim, D.-S. Effect of carbon nanotube addition on tribological behavior of UHMWPE. Tribol. Lett. 2004, 16, 305-309.

81. Kanagaraj, S.; Mathew, M.T.; Fonseca, A.; Oliveira, M.S.A.; Simões, J.A.O.; Rocha, L.A. Tribological characterisation of carbon nanotubes/ultrahigh molecular weight polyethylene composites: The effect of sliding distance. Int. J. Surf. Sci. Eng. 2010, 4, 305-321.

82. Meschi Amoli, B.; Ahmad Ramazani, S.A.; Izadi, H. Preparation of ultrahigh-molecular-weight polyethylene/carbon nanotube nanocomposites with a ziegler-Natta catalytic system and investigation of their thermal and mechanical properties. J. Appl. Polym. Sci. 2012, 125, E453-E461.

83. Maksimkin, A.V.; Kaloshkin, S.D.; Kaloshkina, M.S.; Gorshenkov, M.V.; Tcherdyntsev, V.V.; Ergin, K.S.; Shchetinin, I.V. Ultra-high molecular weight polyethylene reinforced with multi-walled carbon nanotubes: Fabrication method and properties. J. Alloys Compd. 2012, 536, 538-540.

84. Fonseca, M.A.; Subramani, K.; Oliveira, M.S.A.; Simões, J.A. Enhanced UHMWPE reinforced with mwcnt through mechanical ball-milling. Defect Diffus. Forum 2011, 312-315, 1238-1243.

85. Lee, J.K.; Rhee, K.Y.; Lee, J.H. Wear properties of 3-aminopropyltriethoxysilanefunctionalized carbon nanotubes reinforced ultra high molecular weight polyethylene nanocomposites. Polymer Eng. Sci. 2010, 50, 1433-1439.

86. Liu, Y.; Sinha, S.K. Wear performances and wear mechanism study of bulk UHMWPE composites with nacre and cnt fillers and pfpe overcoat. Wear 2013, 300, 44-54.

87. Martínez-Morlanes, M.J.; Castell, P.; Alonso, P.J.; Martinez, M.T.; Puértolas, J.A. Multi-walled carbon nanotubes acting as free radical scavengers in gamma-irradiated ultrahigh molecular weight polyethylene composites. Carbon 2012, 50, 2442-2452.

88. Balani, K.; Anderson, R.; Laha, T.; Andara, M.; Tercero, J.; Crumpler, E.; Agarwal, A. Plasma-sprayed carbon nanotube reinforced hydroxyapatite coatings and their interaction with human osteoblasts in vitro. Biomaterials 2007, 28, 618-624.

89. Wang, Q.; Zhang, D.; Ge, S. Biotribological behavior of ultra-high molecular weight polyethylene composites containing ti ina hip joint simulator. Proc. Inst. Mech. Eng. Part J. 2007, 221, 307-313.

90. Ge, S.; Wang, S.; Huang, X. Increasing the wear resistance of UHMWPE acetabular cups by adding natural biocompatible particles. Wear 2009, 267, 770-776.

91. Xie, X.L.; Tang, C.Y.; Chan, K.Y.Y.; Wu, X.C.; Tsui, C.P.; Cheung, C.Y. Wear performance of ultrahigh molecular weight polyethylene/quartz composites. Biomaterials 2003, 24, 1889-1896.

92. Liu, Y.; Sinha, S.K. Wear performances of uhmwpe composites with nacre and cnts, and pfpe coatings for bio-medical applications. Wear 2013, 300, 44-54.

93. Habibovic, P.; van der Valk, C.M.; van Blitterswijk, C.A.; de Groot, K.; Meijer, G. Influence of octacalcium phosphate coating on osteoinductive properties of biomaterials. J. Mater. Sci. Mater. Med. 2004, 15, 373-380.

94. Calderon, V.S.; Sánchez-López, J.C.; Cavaleiro, A.; Carvalho, S. Biotribological behavior of Ag-Zrcxn1-x coatings against uhmwpe for joint prostheses devices. J. Mech. Behav. Biomed. Mater. 2015, 41, 83-91. 
95. Firouzi, D.; Youssef, A.; Amer, M.; Srouji, R.; Amleh, A.; Foucher, D.A.; Bougherara, H. A new technique to improve the mechanical and biological performance of ultra high molecular weight polyethylene using a nylon coating. J. Mech. Behav. Biomed. Mater. 2014, 32, 198-209.

96. Ruan, F.; Bao, L. Mechanical enhancement of uhmwpe fibers by coating with carbon nanoparticles. Fibers Polymer 2014, 15, 723-728.

97. Zhang, Y.-C.; He, J.-X.; Wu, H.-Y.; Qiu, Y.-P. Surface characterization of helium plasma treated nano-sio2 sol-gel coated uhmwpe filaments by contact angle experiments and atr-ftir. J. Fiber Bioeng. Inf. 2010, 3, 50-54.

98. Chu, P.K.; Chen, J.Y.; Wang, L.P.; Huang, N. Plasma-surface modification of biomaterials. Mater. Sci. Eng. 2002, 36, 143-206.

99. Puértolas, J.A.; Martínez-Nogués, V.; Martínez-Morlanes, M.J.; Mariscal, M.D.; Medel, F.J.; López-Santos, C.; Yubero, F. Improved wear performance of ultra high molecular weight polyethylene coated with hydrogenated diamond like carbon. Wear 2010, 269, 458-465.

100. He, W.; Gonsalves, K.E.; Halberstadt, C.R. Micro/nanomachining and fabrication of materials for biomedical applications. In Biomedical Nanostructures; John Wiley \& Sons, Inc.: Hoboken, NJ, USA, 2007; pp. 25-47.

101. Dong, H.; Bell, T. State-of-the-art overview: Ion beam surface modification of polymers towards improving tribological properties. Surf. Coat. Technol. 1999, 111, 29-40.

102. Boampong, D.K.; Green, S.M.; Unsworth, A. N+ ion implantation of ti6al4v alloy and UHMWPE for total joint replacement application. J. Appl. Biomater. Biomech. 2003, 1, 164-171.

103. Qiu, Z.-Y.; Chen, C.; Wang, X.-M.; Lee, I.-S. Advances in the surface modification techniques of bone-related implants for last 10 years. Regen. Biomater. 2014, 1, 67-79.

104. Ensinger, W.; Höchbauer, T.; Rauschenbach, B. Treatment uniformity of plasma immersion ion implantation studied with three-dimensional model systems. Surf. Coat. Technol. 1998, 103-104, 218-221.

105. Powles, R.C.; McKenzie, D.R.; Fujisawa, N.; McCulloch, D.G. Production of amorphous carbon by plasma immersion ion implantation of polymers. Diam. Relat. Mater. 2005, 14, 1577-1582.

106. Shi, W.; Li, X.Y.; Dong, H. Improved wear resistance of ultra-high molecular weight polyethylene by plasma immersion ion implantation. Wear 2001, 250, 544-552.

107. Zhang, B.; Huang, W.; Wang, J.; Wang, X. Comparison of the effects of surface texture on the surfaces of steel and UHMWPE. Tribol. Int. 2013, 65, 138-145.

108. Kustandi, T.S.; Choo, J.H.; Low, H.Y.; Sinha, S.K. Texturing of UHMWPE surface via nil for low friction and wear properties. J. Phys. D 2010, 43, 015301.

109. Tan, J.; Saltzman, W.M. Biomaterials with hierarchically defined micro- and nanoscale structure. Biomaterials 2004, 25, 3593-3601.

110. Ito, H.; Kaneda, K.; Yuhta, T.; Nishimura, I.; Yasuda, K.; Matsuno, T. Reduction of polyethylene wear by concave dimples on the frictional surface in artificial hip joints. J. Arthropl. 2000, 15, $332-338$.

111. Kurella, A.; Dahotre, N.B. Review paper: Surface modification for bioimplants: The role of laser surface engineering. J. Biomater. Appl. 2005, 20, 5-50.

112. Chyr, A.; Qiu, M.; Speltz, J.; Jacobsen, R.L.; Sanders, A.P.; Raeymaekers, B. A patterned microtexture to reduce friction and increase longevity of prosthetic hip joints. Wear 2014, 315, 51-57. 
113. Lopez-Cervantes, A.; Dominguez-Lopez, I.; Barceinas-Sanchez, J.D.; Garcia-Garcia, A.L. Effects of surface texturing on the performance of biocompatible UHMWPE as a bearing material during in vitro lubricated sliding/rolling motion. J. Mech. Behav. Biomed. Mater. 2013, 20, 45-53.

114. Sagbas, B.; Durakbasa, M.N. Effect of surface patterning on frictional heating of vitamin E blended UHMWPE. Wear 2013, 303, 313-320.

115. Wang, X.; Wang, J.; Zhang, B.; Huang, W. Design principles for the area density of dimple patterns. Proc. Inst. Mech. Eng. Part J. 2014, doi:10.1177/1350650114531939.

116. Kelly, N.H.; Fu, R.H.; Wright, T.M.; Padgett, D.E. Wear damage in mobile-bearing TKA is as severe as that in fixed-bearing TKA. Clin. Orthop. Relat. Res. 2011, 469, 123-130.

(C) 2015 by the authors; licensee MDPI, Basel, Switzerland. This article is an open access article distributed under the terms and conditions of the Creative Commons Attribution license (http://creativecommons.org/licenses/by/4.0/). 